\title{
Should medical educators rethink on-the-spot quizzing?
}

\author{
Cite as: CMAJ 2021 August 3;193:E1182-3. doi: 10.1503/cmaj.1095954
}

Posted on cmajnews.com on July 20, 2021

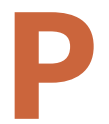

osing on-the-spot questions to probe the limits of trainees' knowledge, also known as "pimping," is a longstanding teaching method in medicine. It's part pop quiz, part trial by fire. But with growing concerns about bullying and burnout, some physicians and trainees are questioning the value of the technique in modern medical education.

Proponents say high-stress, rapid-fire questioning teaches trainees to think fast under pressure and ensures they'll remember key concepts for the rest of their careers. In the Journal of Surgical Education, Drs. James Healy and Peter Yoo described the discomfort of pimping as a kind of inoculation. "Although sometimes unpleasant, this type of education is truly a long-term kindness to the student, much like a vaccination creates temporary discomfort to achieve a durable gain."

Done badly, however, critics argue that pimping can easily cross the line into teaching by humiliation, particularly when senior physicians question students in ways that shame them for their lack of knowledge.

One Australian study found that nearly three-quarters of a student cohort across two medical schools had experienced such intimidation; as a result, they were less likely to engage in future ward rounds or the specialty in question. "More effective and respectful approaches to teaching need to be adopted," the authors concluded.

Dr. Ashley Palmer will never forget the first time a medical school preceptor quizzed her in front of her peers.

While conducting a cardiac exam on a simulated patient in first year, "I remember

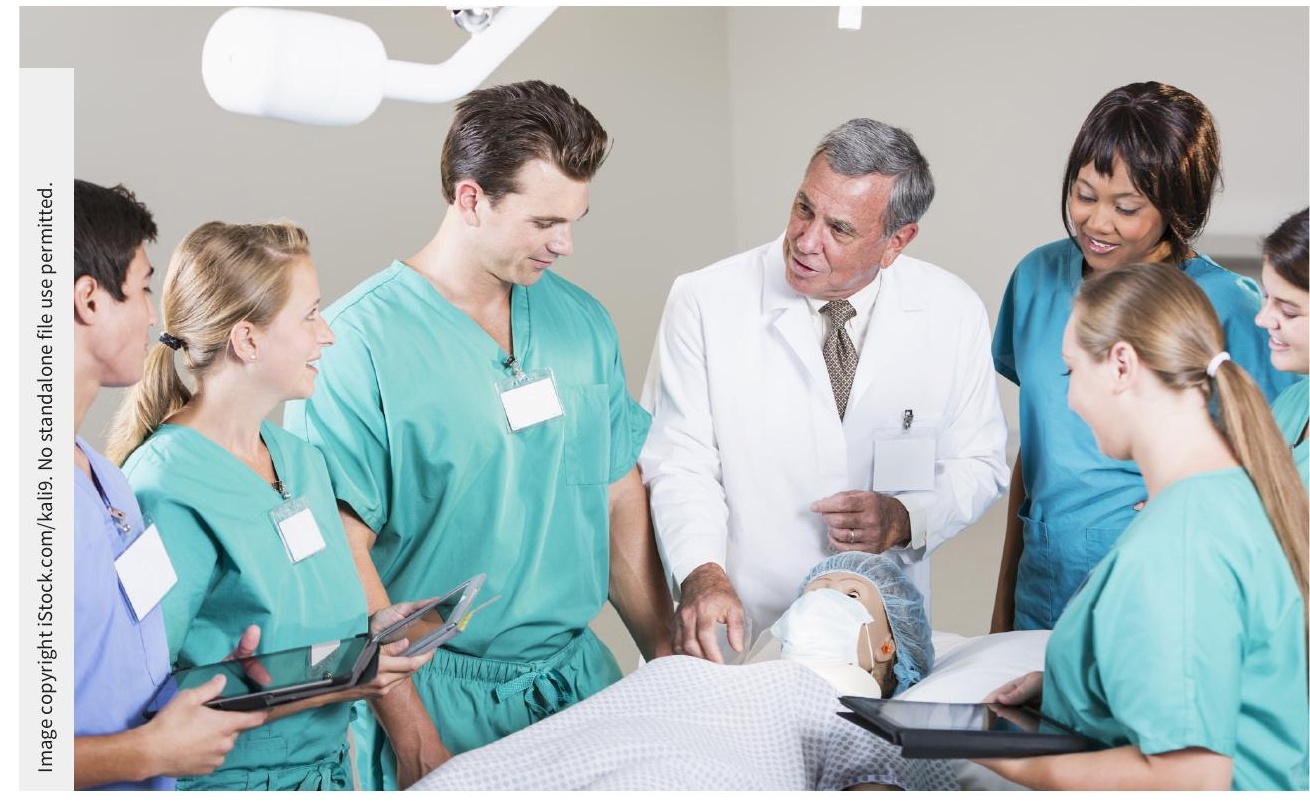

Concerns about trainee wellbeing have sparked debate about the medical education technique commonly called "pimping."

a preceptor asking me the six different characteristics of a heart murmur," said Palmer, now a family medicine resident in Chilliwack, Sask. "I got a few of them, but I didn't know all of them. The preceptor said he was disappointed with my lack of knowledge."

He went on to ask the simulated patient questions about Palmer's performance until the patient retorted, "Are you trying to get me to say she was awful?"

Such experiences may motivate some students, but not necessarily in lasting or positive ways. In a qualitative study of 13 medical students at the University of Saskatchewan, Palmer found that pimping mainly motivated students to impress their preceptors and avoid embarrassment. Without the potential for reward or retribution, students became "completely disengaged," she said.
According to Palmer, who presented her findings at the 2019 Canadian Conference on Medical Education, pimping also discouraged students from asking questions and led many to feel anxious, guilty or inadequate. "It didn't help in the long term."

Another small qualitative study from the University of British Columbia observed that students facing directed questioning were more often concerned with image management than optimizing their learning.

Some critics argue this "aggressive style of Socratic questioning" is no longer relevant now that modern medical education is shifting away from rote memorization. Others say the term "pimping" itself is outmoded, given the sexist and exploitative connotations linking pimping with prostitution. 
According to Drs. David Chen and Kelsey Priest, "it is surprising that various articles exploring pimping's relationship to medical student mistreatment do not acknowledge that women and those of non-binary gender identities may experience the practice differently from men."

Indeed, one study of faculty at Johns Hopkins University found that more aggressive "pimpers" tended to be younger, male specialists who reported "lower quality of life."

Meanwhile, limited quantitative research suggests trainees' overall experience of the practice is complicated.

One survey of University of Michigan medical students graduating in 2020 found that most $(89 \%)$ valued probing questions even though nearly two in five (39\%) felt humiliated when they didn't know the answers. Notably, only a small minority of students (5\%) believed that faculty asked questions expressly to humiliate them.

Another survey of third- and fourthyear medical students at the University of Washington found that "Socratic teaching" or pimping was not a risk factor for humiliation if learners received orientation on the practice.

"If it's done tactfully and politely and not attached to judgment, I think it's a good way to know where students stand, and preceptors can see where the limits of their knowledge are," said Dr. Jack
Yuan, National Officer of Wellness for the Canadian Federation of Medical Students (CFMS). Meanwhile, CFMS can advocate for better policies and make recommendations for handling mistreatment, Yuan said.

Despite criticism of the aggressive, oneway questioning usually associated with the term pimping, there isn't much research on alternative approaches. Some have proposed a return to the Socratic roots of the practice emphasizing dialogue to promote critical thinking skills.

"If you really look at the Socratic method, the idea is that you're asking questions to guide somebody to finding the answer or figuring out the answer themselves," explained Dr. Peter Kwan, an assistant clinical professor and surgery clerkship coordinator at the University of Alberta. Kwan said he encourages his students to ask their own questions to promote dialogue and give them some control in the conversation.

According to Dr. Nikita-Kiran Singh, a Toronto-based internal medical resident, explaining teaching methods upfront is an important way to create a safe learning environment. "Socratic questioning should leave the learner feeling empowered and feel like the focus has been on the learning process."

Singh gives the example of a discussion she had with a student about a patient with anemia who experienced a drop in haptoglobin. Hemolysis was one possible explanation for the drop, but when Singh asked the student about other potential causes, he confessed he didn't know.

Singh then asked the student where haptoglobin is produced, to which he responded, "in the liver." So, Singh asked again, "Knowing that, when do you think haptoglobin could be low without hemolysis?" This time, she said, the student responded immediately, "If someone has liver failure."

According to Singh, thoughtful questioning can help students arrive at answers without shaming them about gaps in their knowledge. "I was able to see that he actually did know the foundational pieces that would allow him to make those connections. But if you just ask the one question [and move on when a student gets it wrong], you wouldn't know that."

\section{Diana Duong, CMAJ}

Content licence: This is an Open Access article distributed in accordance with the terms of the Creative Commons Attribution (CC BY-NC-ND 4.0) licence, which permits use, distribution and reproduction in any medium, provided that the original publication is properly cited, the use is noncommercial (i.e., research or educational use), and no modifications or adaptations are made. See: https://creativecommons.org/ licenses/by-nc-nd/4.0/ 